\title{
Breathlessness after percutaneous biliary drainage
}

\author{
H Patel, K S Hindle, G Tsavellas, A Huang
}

Answers on $p 795$.

Department of Academic Surgery, Chelsea and

Westminster Hospital, London SW10 9NH, UK

H Patel

G Tsavellas

A Huang

Wycombe Hospital, High Wycombe, Buckinghamshire K S Hindle

Correspondence to: Mr Huang

a.huang@ic.ac.uk

Submitted 14 August 2000 Accepted 17 October 2000

Answers on $p 795$.

Renal Unit, Glasgow Royal Infirmary, Glasgow, Scotland

N Joss

K Simpson

Correspondence to: Dr Nicola Joss, Renal Unit, Glasgow Royal Infirmary, 84 Castle Street, Glasgow G4 OSF, UK

njoss@compuserve.com

Submitted 22 March 2000 Accepted 6 November 2000 progressive jaundice and weight loss. She also had generalised pruritus and was passing dark urine and pale stools. On examination there was a palpable right upper quadrant abdominal mass. Plasma bilirubin level was $56 \mu \mathrm{mol} / 1$ and alkaline phosphatase was $350 \mathrm{U} / 1$. Serum amylase was within normal limits. Abdominal ultrasound scan showed a dilated biliary tree

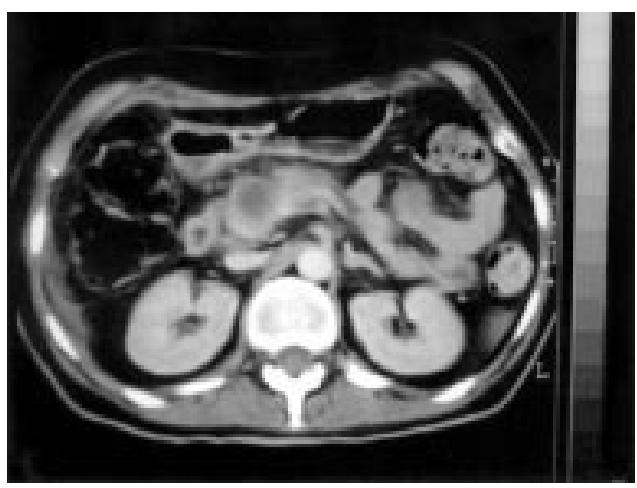

Figure 1 Abdominal computed tomogram.

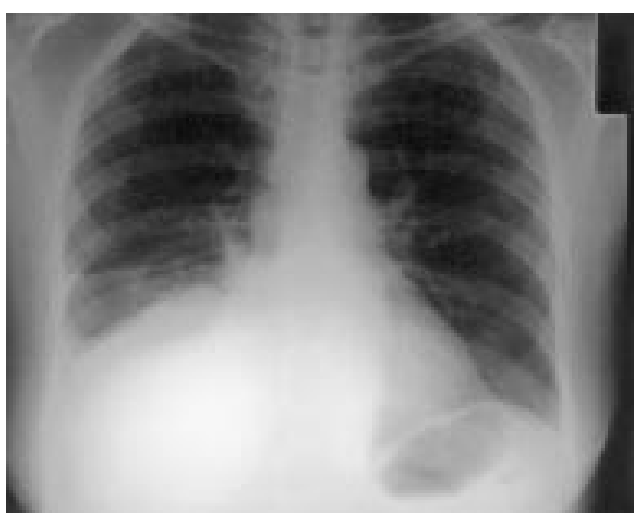

Figure 2 Thoracic radiograph.
A 77 year old woman presented with painless

\author{
N Joss, K Simpson
}

A 37 year old women presented with a 10 year history of episodes of weakness and palpitations. On one or two occasions each year she was admitted to her local hospital where her serum potassium concentration was always below the reference range with the lowest concentration reported at $2.2 \mathrm{mmol} / 1$ (3.5-5.0 $\mathrm{mmol} / \mathrm{l})$. The episodes were terminated with intravenous potassium. At other times she had mild weakness on exertion and occasional palpitations. These symptoms disappeared with oral potassium supplements. She was always normotensive. She had no diarrhoea or vomiting, her drug history consisted of oral amiloride

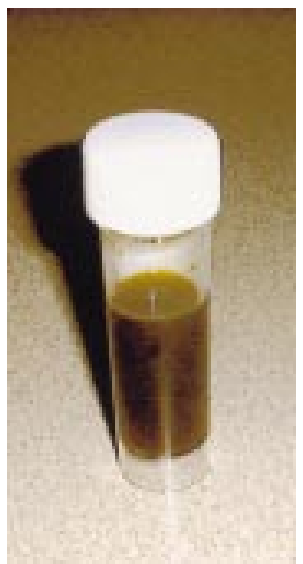

Figure 3 Pleural aspirate.

and a distended gallbladder but there was no evidence of gallstones. Abdominal computed tomography was performed (fig 1). The patient underwent an endoscopic retrograde cholangiopancreaticogram (ERCP) and insertion of a biliary stent, with resolution of the jaundice.

Ten days later the patient became jaundiced again and an abdominal ultrasound suggested stent occlusion with recurrent biliary tree dilatation. Percutaneous transhepatic cholangiography (PTC) with external biliary drainage was performed. The patient gradually became short of breath with right sided pleuritic pain and a thoracic radiograph was obtained (fig 2). Thoracocentesis was performed and the pleural aspirate is shown (fig 3 ).

\section{Questions}

(1) What is the most likely cause of her jaundice and why was this suspected clinically?

(2) What complication of PTC has occurred?

(3) What is the treatment of this complication?

\section{Episodic weakness in a young woman}

$15 \mathrm{mg} /$ day and a variable amount of effervescent potassium chloride supplements. She had a sister who had one minor episode of weakness but had not been investigated. She was referred to a renal unit for further investigations and to obtain a diagnosis.

On examination she looked well, with a blood pressure of $115 / 70 \mathrm{~mm} \mathrm{Hg}$, she was clinically euvolaemic, she had no signs of self induced vomiting, and she was not cushingoid.

Her initial investigations revealed the following serum electrolyte concentrations: sodium $137 \mathrm{mmol} / 1$ (135-145), potassium $3.0 \mathrm{mmol} / 1$ (3.5-5.0), chloride $100 \mathrm{mmol} / \mathrm{l}$ (97-107), 
bicarbonate $30 \mathrm{mmol} / \mathrm{l}$ (23-30), urea 4.9 $\mathrm{mmol} / \mathrm{l}$ (2.5-8.0), creatinine $90 \mu \mathrm{mol} / 1$ (40130), and calcium $2.6 \mathrm{mmol} / \mathrm{l}(2.2-2.6)$. Arterial blood gases: arterial oxygen tension $12 \mathrm{kPa}$ (12-15), arterial carbon dioxide tension $4.8 \mathrm{kPa}(4.4-5.6)$, and hydrogen ion $32 \mathrm{nmol} / 1$ (35-45). Her 24 hour urine sample performed when her serum potassium was $3.0 \mathrm{mmol} / 1$ revealed a urinary potassium of $63 \mathrm{mmol} / 24$ hours. Her plasma cortisol and thyroid function tests were normal. A supine plasma renin activity of $32.8 \mathrm{ng} / \mathrm{ml} /$ hour $(0.5-2.4)$ and aldosterone of $990 \mathrm{pmol} / \mathrm{l}(100-400)$ and ambulatory values of $40.4 \mathrm{ng} / \mathrm{ml} /$ hour $(0.98-$ 4.18) and $2500 \mathrm{pmol} / 1$ (400-800) were measured.

\section{Questions}

(1) What is the metabolic abnormality?

(2) What are the differential diagnoses?

(3) What investigations will help distinguish between the possible diagnoses?

(4) What is the likely diagnosis?

\section{From cutaneous ulceration to chronic diarrhoea}

\section{Sims, C Hendrickse, N Michell}

Answers on $p 797$.

\author{
Department of \\ Gastroenterology, \\ Birmingham Heartlands \\ Hospital, Bordesley \\ Green, Birmingham \\ B9 9SS, UK \\ D Sims \\ C Hendrickse \\ N Michell \\ Correspondence to: \\ Dr Michell
}

Submitted 10 January 2001 Accepted 22 February 2001
A 48 year old woman presented with a 10 day history of painful red nodules over her face, trunk, and limbs which rapidly enlarged before developing central ulceration. She was otherwise well with no complaints. She had received four days of oral flucloxacillin but otherwise was on no medication. There was no past medical history of note. Examination revealed deep cutaneous ulcers with purplish undermined edges and slough at the ulcer bases (fig 1). Ulcer swabs and blood cultures failed to grow any organisms. Chest radiography, full blood count, and biochemical profile were normal, but the $\mathrm{C}$ reactive protein was markedly raised at $380 \mathrm{mg} / 1$. Complement C3 and C4 levels and $\operatorname{IgG}, \operatorname{IgA}$, and $\operatorname{Ig} M$ titres were normal. Antinuclear antibodies, DNA antibodies (single and double strand), and neutrophil cytoplasmic antibodies were negative. Neutrophil function tests were normal (as assessed by respiratory burst chemiluminescence). A skin biopsy showed a predominantly neutrophilic infiltrate of the dermis with a leucocytoclastic vasculitis. She was treated with 14 days of flucloxacillin and the ulcers healed over the next month.

Two years later she developed diarrhoea after a chicken meal. After one week she again developed cutaneous ulcers over her face, trunk, and limbs. She presented six weeks later with weight loss, abdominal pains, multiple

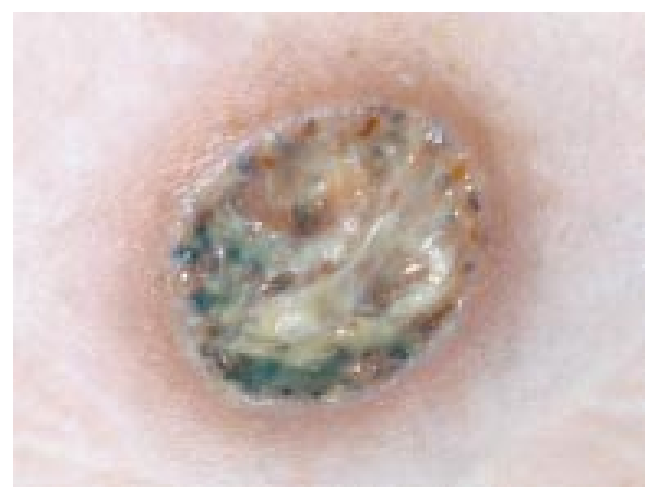

Figure 1 Typical cutaneous lesion (reproduced with permission).

skin ulcers, and passing faeces through her vagina. On examination the skin lesions were as before, there was tenderness in the left iliac fossa, and a rectovaginal fistula was present. Inflammatory markers were raised but ulcer, stool, and blood cultures were sterile.

\section{Questions}

(1) What is the skin lesion shown in fig 1?

(2) What is the gastrointestinal diagnosis?

(3) What other skin lesions are associated with this disease? 